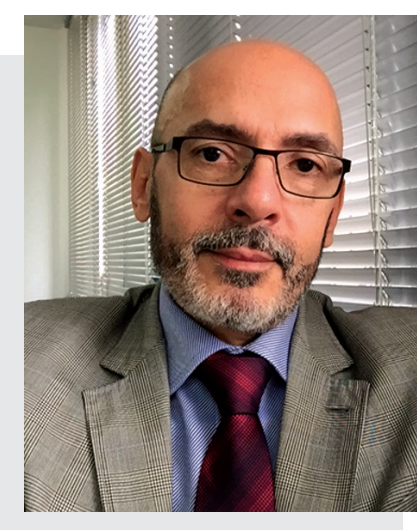

\title{
Obesity and Atrial Fibrillation
}

\section{Obesidade e Fibrilação Atrial}

\author{
J. Tarcísio Medeiros de Vasconcelos ${ }^{1, *}$
}

Atrial fibrillation is currently a central issue in the universe of cardiac arrhythmias. The increase in life expectancy that brought a substantial increase in its prevalence in the general population ${ }^{1}$ implied a marked deepening in the understanding of its electrophysiological mechanisms, in the identification of determining factors or potentiation of its occurrence and obviously in the development of effective strategies of treatment and prevention of its complications. Since the classic study of Wijffels et al., published in 1995 (Atrial Fibrillation Begets Atrial Fibrillation) ${ }^{2}$ which experimentally demonstrated that atrial frequencies artificially imposed to the atrial myocardium imply marked electrophysiological changes determining the very occurrence of atrial fibrillation, it became clear that once arrhythmia is initiated it potentiates its own occurrence and a constant process of feedback, whose final outcome over time is the installation of arrhythmia in a permanent form. However, for atrial fibrillation to occur, the presence of an adequate electrophysiological environment is necessary, consequent to the presence of several elements that aggress the atrial myocardium under the electrical and structural aspects.

Obesity is a factor identified as an independent risk marker for the occurrence of atrial fibrillation and its progression from a paroxysmal to permanent form. In the Framingham Health Study, obesity implied a risk of about 1.5 times greater for the development of atrial fibrillation; the increase of 1 point in body mass index was related to a $4 \%$ increase in the chance of developing arrhythmia ${ }^{3}$. Similarly, obesity is also implicated in a greater chance of evolution of arrhythmia itself in individuals who already have atrial fibrillation. In a 21-year-old observational study, Tsang et al. demonstrated that obese individuals with paroxysmal atrial fibrillation have 1.5 (BMI 30 to $34.9 \mathrm{~kg} / \mathrm{m}^{2}$ ) to 1.9 times (BMI > $35 \mathrm{~kg} / \mathrm{m}^{2}$ - morbidly obese) more chances of progression to permanent atrial fibrillation than nonobese individuals ${ }^{4}$. The mechanisms involved in this effect are not clearly understood. It is possible that the release of inflammatory mediators, neurohumoral factors and hemodynamic elements play a determining role in this susceptibility ${ }^{5-9}$. It is also possible that sleep apnea, often related to obesity, may have a significant determining role in the occurrence of atrial fibrillation in these individuals ${ }^{10}$.

Although the association between obesity and atrial fibrillation is well recognized, the benefits of weight loss in the treatment of individuals who already have arrhythmia have only recently begun to be evaluated. In the LEGACY study published in $2015^{11}, 355$ individuals with body mass index $\geq 27 \mathrm{~kg} / \mathrm{m}^{2}$ and atrial fibrillation were stimulated to weight loss and followed for about 5 years. Weight loss of $10 \%$ or more led to a substantial reduction in atrial fibrillation burdens and a significant increase in the rate of arrhythmia-free patients in follow-up. Individuals who achieved this weight loss target had more than six times the chance to remain free of atrial fibrillation than those who did not achieve this rate of loss. In a more recent publication, complementing the LEGACY study itself, the impact of the magnitude of weight loss on the progression of atrial fibrillation exteriorization ${ }^{12}$ was evaluated. An inverse correlation between the magnitude of the weight loss and the progression of arrhythmia has been demonstrated. Patients with weight loss greater than or equal to $10 \%$ had a substantially lower rate of progression of atrial fibrillation from the paroxysmal to the persistent form, a higher rate of regression from the persistent to the paroxysmal form and also a lower rate of occurrence of arrhythmia itself, when compared to those patients who had weight loss below this value.

1.Centro Avançado de Ritmologia e Eletrofisiologia - São Paulo (SP) - Brasil.

*Correspondence author: tarr@terra.com.br

ORCID: Vasconcelos JTM (iD https://orcid.org/0000-0002-5152-2648 
The impact of obesity is also felt in the results of the atrial fibrillation treatment itself. In obese and morbidly obese patients undergoing interventional treatment through percutaneous ablation by isolation of the pulmonary veins, failure rates have been high, reaching around $60 \%$ in 1 year of follow-up ${ }^{13}$. The treatment of obesity before the treatment of atrial fibrillation by ablation seems to improve the results of the procedure. In a study by Donnellan et al., published in 2019 ${ }^{14}$, 51 morbidly obese with BMI $\geq 40 \mathrm{~kg} / \mathrm{m}^{2}$, and atrial fibrillation were submitted to treatment of obesity by bariatric surgery before performing percutaneous ablation for treatment of arrhythmia. The sample was paired in a 2:1 pattern according to age and gender to 102 nonobese patients and 102 morbidly obese patients not treated by bariatric surgery, also submitted to percutaneous ablation. In about 30 months of follow-up, the recurrence rates of atrial fibrillation were $20 \%$ in obese patients treated by bariatric surgery, $24 \%$ in nonobese patients and $55 \%$ in morbidly obese patients not treated by bariatric surgery $(\mathrm{p}<0.0001)$.

In summary, obesity increases the risk for atrial fibrillation, accelerates its progression in those patients already with arrhythmia and worsens treatment results. In its turn, the weight reduction in those with atrial fibrillation reduces its risk of occurrence in those who do not have arrhythmia, interferes with the natural history of those individuals with arrhythmia and improves the results of treatment by ablation. Aggressive weight reduction, therefore, should be a cornerstone in preventing and treating this multifaceted arrhythmia.

\section{REFERENCES}

1. Staerk L, Wang B, Preis SR, Larson MG, Lubitz SA, Ellinor, PT. Lifetime risk of atrial fibrillation according to optimal, borderline, or elevated levels of risk factors: cohort study based on longitudinal data from the Framingham Heart Study. BMJ. 2018;361:1-10. https://doi. org/10.1136/bmj.k1453

2. Wijfels MCEF, Kirchhof CJHJ, Dorland R, Allessie MA. Atrial Fibrillation Begets Atrial Fibrillation. A Study in Awake Chronically Instrumented Goats. Circulation. 1995;92(7):1954-68. https://doi.org/10.1161/01.cir.92.7.1954

3. Wang TJ, Parise H, Levy D, D'Agostino RB, WolfPA, Vasan RS, etal. Obesity and the risk of new-onset atrial fibrillation. JAMA. 2004;292(20):24717. https://doi.org/10.1001/jama.292.20.2471

4. Tsang TS, Barnes ME, Miyasaka Y, Cha SS, Bailey KR, Verzosa GC, et al. Obesity as a risk factor for the progression of paroxysmal to permanent atrial fibrillation: a longitudinal cohort study of 21 years. Eur HeartJ. 2008;29(18):2227-33. https://doi.org/10.1093/eurheartj/ehn324

5. Juge-Aubry CE, Henrichot E, Meier CA. Adipose tissue: a regulator of inflammation. Best Pract Res Clin Endocrinol Metab. 2005;19(4):54766. https://doi.org/10.1016/j.beem.2005.07.009

6. Warnberg J, Nova E, Moreno LA, Romeo J, Mesana MI, Ruiz JR, et al. Inflammatory proteins are related to total and abdominal adiposity in a healthy adolescent population: the AVENA Study. Am J Clin Nutr. 2006;84(3):505-12. https://doi.org/10.1093/ajcn/84.3.505

7. Kahn SE, Zinman B, Haffner SM, O'Neill MC, Kravitz BG, Yu D, et al. Obesity is a major determinant of the association of C-reactive protein levels and the metabolic syndrome in type 2 diabetes. Diabetes. 2006;55(8):2357-64. https://doi.org/10.2337/db06-0116

8. Wang TJ, Larson MG, Levy D, Benjamin EJ, Leip EP, Wilson PW, et al. Impact of obesity on plasma natriuretic peptide levels. Circulation. 2004;109(5):594-600. https://doi.org/10.1161/01.CIR.0000112582.16683.EA

9. Wildman RP, Farhat GN, Patel AS, Mackey RH, Brockwell S, Thompson T, et al. Weight change is associated with change in arterial stiffness among healthy young adults. Hypertension. 2005;45(2):187-92. https://doi.org/10.1161/01.HYP.0000152200.10578.5d

10. Gami AS, Hodge DO, Herges RM, Olson EJ, Nykodym J, Kara T, et al. Obstructive sleep apnea, obesity, and the risk of incident atrial fibrillation. J Am Coll Cardiol. 2007;49(5):565-71. https://doi.org/10.1016/j.jacc.2006.08.060

11. Pathak RK, Middeldorp ME, Meredith M, Mehta AB, Mahajan R, Wong CX, et al. Long-term effect of goal directed weight management in an atrial fibrillation cohort: a long-term follow-up study (LEGACY). J Am Coll Cardiol. 2015;65(20):2159-69. https://doi.org/10.1016/j. jacc.2015.03.002

12. Middeldorp ME, Pathak RK, Meredith M, Mehta AB, Elliott AD, Mahajan R, et al. Prevention and regressive effect of weight-loss and risk factor modification on atrial fibrillation: the REVERSE-AF study. Europace. 2018;20(12):1929-35. https://doi.org/10.1093/europace/euy117

13. Sivasambu B, Balouch MA, Zghaib T, Bajwa RJ, Chrispin J, Berger RD, et al. Increased rates of atrial fibrillation recurrence following pulmonary vein isolation in overweight and obese patients. J Cardiovasc Electrophysiol. 2018;29(2):239-45. https://doi.org/10.1111/jce.13388

14. Donnellan E, Wazni O, Kanj M, Hussein A, Baranowski B, Lindsay B, et al. Outcomes of atrial fibrillation ablation in morbidly obese patients following bariatric surgery compared with a nonobese cohort. Circ Arrhythm Electrophysiol. 2019;12(10):1-6. https://doi.org/10.1161/ CIRCEP.119.007598 